\title{
Research on Estimation for Architectural Project Cost Based on BP
}

\section{Neural Network}

\author{
Jing Zhao ${ }^{1 \mathrm{a}}$, Li Zhao ${ }^{2 \mathrm{~b}}$ and Yi-wei Ren ${ }^{3 \mathrm{c}}$ \\ ${ }^{1}$ Department of Logistics Management (Group) , Agricultural University of Hebei,Baoding,China \\ ${ }^{2}$ Institute of Land and Resources, Agricultural University of Hebei, Baoding,China \\ ${ }^{3}$ Hebei Yong Cheng Engineering Project Management Co. Ltd.,Baoding, China \\ azhaojing0000180@sina.com, 'zhaol i1606@126.com, 610062932@qq.com
}

Keywords: Frame structure; BP neural network; Project cost; Cost index

Abstract. The estimation of project cost affects the rationality of project invitation for bid. According to the principles of construction budget estimate, the main character index is identified as a model example, and the char index is transformed into a numeric character index. At the same time, the BP neural network improved by gradient descent momentum and an adaptive learning rate is introduced to estimate the project cost which involved the cost index, and the prototype data is presented and analyzed in the neural network to establish the cost estimation model. The results show that the model is feasible and credible completely, the cost error of which is much better than that in the relevant document, and it could provide a more efficient path for fast estimating of the project cost.

\section{Introduction}

In the construction project bidding activities, the ability to quickly and reliably estimate project cost directly affects the rationality bidding decisions. The traditional project valuation method is the use of BOQ calculation. Due to many rules, complex and cumbersome calculation, heavy workload and time-consuming of this method, it is difficult to meet the rapidly changing market changes. For such problems, in recent years, fuzzy theory, expert systems, case-based reasoning, gray system theory, genetic algorithm and neural network have been widely used[1]. Compared with other method, neural network has strong adaptability, good fault tolerance, computing speed, and is good at solving the outstanding merits of complex nonlinear modeling problems, which can be more efficient and effective handling multivariate nonlinear problems[2]. For the problem of the construction project valuation, combined with the advantages of neural networks, this paper proposed a estimation method for architectural project cost based on BP neural network.

\section{The quantitative of architecture project feature indexes}

\section{The determination of indexes.}

The civil architecture project generally is composed by the foundation, walls, floors, roofs, doors, windows and other basic components. Its construction cost depends on the kind of project, the amount of major projects, the size, type and price levels and other factors. However, the size of the actual project is determined by the architecture structure parameters of the project design. According to the principles of construction project budget, the project cost factors impacted greatly to project cost and the architecture structure parameters are selected as the main feature indexes, 
which includes basic type, base elevation, engineering category, wall construction, door type, number of doors, window type, number of windows, ground floor, wall decoration, interior decoration, floor number, floor height, construction area, cost index, construction hardware and software environment[3].

\section{The quantitative of indexes.}

The above main feature indexes have two types: the numeric type and the character type. The numeric indexes can be used as network input after data preprocessing. But the character indexes must be transferred in to numeric indexes at first. Such as the basic types, the strip foundation is taken as 1 , the independent foundation is taken as 2 , and the full foundation is taken as 3 . The method of transform for other character feature indexes is similar. This method ca solve the problem that a kind of project feature of a single project only has one kind of category or categories of two adjacent combination of character characteristic feature category to be converted to numerical engineering features. Such as a certain project, its wall uses $5 \%$ concrete and $75 \%$ bricks, the quantitative of the concrete and the brick are respectively 2 and 1, and their combined quantitative value is 1.25 .

The quantitative of the main feature indexes can be arranged according to the specific physical properties, such as the unit cost. The arrangement can be positive sequence (small to large), can also reverse (descending), as long as the arrangement can follow certain rules[4].

As shown in Table. 1, any feature index of a typical architecture project case can be represented as $T_{i}=\left(t_{i 1}, t_{i 2}, t_{i 3}, \cdots, t_{i n}\right)$. For example, the feature indexes of the $i$-th architecture project are strip foundation, brick wall, wooden doors, $6.58 \mathrm{~m}^{2}$ doors of each 100 square meters, aluminum windows, $17.64 \mathrm{~m}^{2}$ windows if each 100 square meters, wear ceramic tile, wall and decorative tile paint, interior decorative paint, 5 floors, the height is 3 meters, the building area is $2737.42 \mathrm{~m}^{2}$, the cost index is 0.8125 , and the project hardware and software environment is good. Thus, the quantitative is expressed as follows:

$$
T_{i}=(2,-2.5,4,1,4,6.58,3,17.64,4,5,2,5,3,2737.42,0.8125,2)
$$

\section{The establishment of the forecasting model}

Transfer the architecture feature indexes into numeric variable, and the training sample is obtained. Through continuously adjusting the BP neural network connection weights between the layers, meet certain requirements or achieve a certain error number of rounds of training, mapping out sample non-linear relationship between the value and the target value. Ultimately establish a stable effective BP neural network model, in order to achieve fast, reliable forecast to new data. This paper used the three-layers BP neural network to forecast the project cost.

\section{The training samples and preprocessing.}

In this paper, the data are required from the literature. The frame structure of multi-storey residential construction is taken as an example. 11 typical projects are selected which are shown in Table. 2. Moreover, take the impact of the cost index and engineering hardware and software environment into the consideration for the influence to the project cost. Because each input data networks often has a different meaning and a different physical dimension, the sample data should be normalized before entering the network and the range of them should be unified. In the process of training, if the weighs of each layer are adjusted only according to the total error, and the greater difference between adjusted data are neglected, the output component that is of small share in the total error will make a larger relative error. Because the building area and the unilateral construction 
cost value is large, we can them divided by 1000. The substrate can be converted to the ground level elevation. Then the normalization function Premnmx and inverse function Postmnmx are used to map input and output data to $[-1,+1]$, so that the network began to give training a component of each input and output components with equal importance.

Table. 1 The quantitative of the character type feature indexes

\begin{tabular}{|c|c|c|c|c|c|c|c|}
\hline $\begin{array}{c}\text { The } \\
\text { quantitative } \\
\text { characteristics } \\
\text { Category }\end{array}$ & 1 & 2 & 3 & 4 & 5 & 6 & 7 \\
\hline Basis type & Independent & Strip & Full & & & & \\
\hline Wall project & Brick & Concrete & & & & & \\
\hline Window type & $\begin{array}{l}\text { Wooden } \\
\text { window }\end{array}$ & $\begin{array}{c}\text { Plastic } \\
\text { window }\end{array}$ & $\begin{array}{c}\text { Aluminum } \\
\text { window }\end{array}$ & & & & \\
\hline Door type & Plywood door & $\begin{array}{l}\text { Plywood } \\
\text { door } \\
\text { Fireproof }\end{array}$ & $\begin{array}{l}\text { Plywood } \\
\text { door }\end{array}$ & Wooden door & $\begin{array}{l}\text { Wooden door } \\
\text { Fireproof }\end{array}$ & $\begin{array}{l}\text { Aluminum } \\
\text { door }\end{array}$ & $\begin{array}{l}\text { Security } \\
\text { Door }\end{array}$ \\
\hline Ground floor & $\begin{array}{c}\text { Cement } \\
\text { mortar }\end{array}$ & Brick floor & $\begin{array}{l}\text { Wood } \\
\text { floor }\end{array}$ & $\begin{array}{c}\text { Wear-resistant } \\
\text { tile }\end{array}$ & $\begin{array}{l}\text { Wear-resistant } \\
\text { brick }\end{array}$ & & \\
\hline $\begin{array}{c}\text { Wall } \\
\text { decoration }\end{array}$ & $\begin{array}{c}\text { Paint } \\
\text { decorative } \\
\text { tiles }\end{array}$ & $\begin{array}{l}\text { Suppressed } \\
\text { flower }\end{array}$ & Spraying & Wall brick & $\begin{array}{l}\text { Brick and } \\
\text { spraying }\end{array}$ & Strip brick & \\
\hline $\begin{array}{c}\text { Interior } \\
\text { decoration } \\
\text { Project }\end{array}$ & Mortar & Latex & $\begin{array}{l}\text { Tiles and } \\
\text { latex paint }\end{array}$ & & & & \\
\hline $\begin{array}{c}\text { hardware and } \\
\text { software } \\
\text { environment }\end{array}$ & General & Good & Excellent & & & & \\
\hline
\end{tabular}

Table. 2 The training sample of the proposed example (The first part)

\begin{tabular}{ccccccccc}
\hline No. & $\mathrm{t}_{\mathrm{i} 1}$ & $\mathrm{t}_{\mathrm{i} 2}$ & $\mathrm{t}_{\mathrm{i} 3}$ & $\mathrm{t}_{\mathrm{i} 4}$ & $\mathrm{t}_{\mathrm{i} 5}$ & $\mathrm{t}_{\mathrm{i} 6}$ & $\mathrm{t}_{\mathrm{i} 7}$ & $\mathrm{t}_{\mathrm{i} 8}$ \\
\hline 1 & 2 & 2.5 & 4 & 1 & 7 & 13.82 & 6.7 & 2.5 \\
2 & 2 & 2.5 & 4 & 1 & 4 & 6.58 & 17.64 & 4 \\
3 & 1 & 2.5 & 3 & 1.5 & 2 & 27.33 & 13.27 & 1 \\
4 & 1 & 2.2 & 4 & 1 & 1 & 15.51 & 12.63 & 5 \\
5 & 1 & 3.8 & 3 & 1.25 & 2 & 45.03 & 15.23 & 1 \\
6 & 2 & 2.2 & 3 & 1 & 4 & 21.15 & 15.74 & 2 \\
7 & 1 & 2.4 & 3 & 1 & 3 & 22.41 & 14.3 & 5 \\
8 & 2 & 1.8 & 4 & 1 & 6 & 20.48 & 11.97 & 5 \\
9 & 3 & 4.5 & 3 & 1 & 3 & 32.64 & 12.12 & 2 \\
10 & 1 & 1.6 & 3 & 1 & 5 & 15.94 & 17.58 & 1 \\
11 & 3 & 5.5 & 3 & 1 & 3 & 11.30 & 15.81 & 1 \\
\hline
\end{tabular}


Table. 2 The training sample of the proposed example (The second part)

\begin{tabular}{ccccccccc}
\hline No. & $\mathrm{t}_{\mathrm{i} 9}$ & $\mathrm{t}_{\mathrm{i} 10}$ & $\mathrm{t}_{\mathrm{i} 11}$ & $\mathrm{t}_{\mathrm{i} 12}$ & $\mathrm{t}_{\mathrm{i} 13}$ & $\mathrm{t}_{\mathrm{i} 14}$ & $\mathrm{t}_{\mathrm{i} 15}$ & $\mathrm{v}$ \\
\hline 1 & 2 & 3 & 5 & 3 & 3.852 & 0.811 & 2 & 1.162 \\
2 & 5 & 2 & 5 & 3 & 2.737 & 0.813 & 2 & 0.907 \\
3 & 4 & 3 & 7 & 3 & 3.172 & 0.814 & 3 & 1.217 \\
4 & 4 & 3 & 5 & 3.5 & 2.391 & 0.820 & 2 & 0.7780 \\
5 & 1 & 3 & 6 & 2.8 & 5.964 & 0.827 & 2 & 1.026 \\
6 & 4 & 2 & 6 & 3.2 & 3.605 & 0.797 & 3 & 0.984 \\
7 & 6 & 3 & 6 & 3.2 & 3.605 & 0.817 & 2 & 0.951 \\
8 & 3 & 3 & 6 & 3 & 2.970 & 0.799 & 1 & 0.813 \\
9 & 4 & 2 & 7 & 3 & 7.557 & 0.822 & 2 & 0.972 \\
10 & 4 & 1 & 7 & 2.8 & 5.932 & 0.812 & 2 & 0.828 \\
11 & 4 & 2 & 7 & 2.8 & 10.705 & 0.822 & 2 & 1.071 \\
\hline
\end{tabular}

\section{Parameters determination.}

The nodes number of the input layer is determined by the number of the feature indexes of the sample data, not artificially set. This paper used Kolmogorov theorems to determine the nodes number of the hidden layer, namely $2 m+1$, where $m$ is the nodes number of the input layer. The nodes number of the output layer is determined by the type of sample target data. And its value is 1 in this paper which represents the unilateral cost.

The determination of node conversion function.

MATLAB toolbox provides three kinds of transfer functions, which are: log-sigmoid, tan-sigmoid and linear function. The first two are nonlinear functions, respectively transfer the input data $(-\infty,+\infty)$ into the output data $[0,1]$ and $[-1,+1]$. In this paper, tan-sigmoid function is selected as the conversion function for all nodes in the hidden layer. The linear function is selected as the conversion function for output layer, which can keep the range of the output data.

\section{The training and learning of the network.}

Network training is the way of network learning. Set the nodes number of input layer in three-layer BP neural network as $n$, the input vector as $X=\left(x_{1}, x_{2}, \cdots, x_{n}\right)$, the nodes number of hidden layer as $p, Z=\left(z_{1}, z_{2}, \cdots, z_{p}\right)$, the nodes number of output layer as $m$, $Y=\left(y_{1}, y_{2}, \cdots, y_{m}\right)$, the weigh value and threshold between input layer and hidden layer as $w_{i j}$ and $\theta_{j}$, the weigh value and threshold between hidden layer and output layer as $v_{j k}$ and $\theta_{j}^{\prime}$. Thus, the output of $j$-th node in hidden layer is expressed as Eq.(1), and the output of $k$-th node in output layer is expressed as Eq.(2).

$$
\begin{aligned}
& z_{j}=f\left|\sum_{i=1}^{n} w_{i j} x_{i}-\theta_{j}\right| \\
& y_{k}=f\left|\sum_{j=1}^{p} v_{j k} z_{j}-\theta_{j}^{\prime}\right|
\end{aligned}
$$


Where the conversion function is tan-sigmoid function: $f(u)=\frac{1}{1+e^{-u}}$.

The training and learning process of BP neural network contains two stages: forward propagation and reverse propagation. Each component of input vector $x_{i}$ produced the output value through forward propagation. Then, compare the error of the output value and expected value. Use a certain algorithm, such as the gradient method, variable gradient method and adaptive learning algorithm with momentum, etc., to adjust the connection weights and thresholds between output layer and hidden layer and between hidden layer and input layer through the network error $E$ back propagation. The network error is gradually reduced and ultimately meet the accuracy requirements or achieve some training iterations.

\section{Network learning and forecasting}

The adaptive learning algorithm traingdx and learning function learngdm are used to train and learn the former 10 samples shown in Table.2. And the eleventh sample is regarded as the testing sample. Set mean square error (MSE) $M S E \leq 0.0001$, learning rate $L_{r}=0.02$. After training iterations 99 times, the MSE is reduced to $9.34751 e^{-5}<0.001$, which indicates that the training result is satisfactory.

The eleventh sample data is used to test the BP neural network, and the test results are shown in Table. 3, where condition one considers both the cost index and project hardware and software environment, condition two only considers the cost index, condition three only considers the project hardware and software environment, condition four does not consider the cost index and project hardware and software environment.

Table. 3 Test results of BP neural network

\begin{tabular}{cccc}
\hline Condition & Expected value & Testing value & Relative error \\
\hline 1 & & 1059.7 & $1.06 \%$ \\
2 & \multirow{2}{*}{1071} & 930 & $13.18 \%$ \\
3 & & 1045.5 & $2.43 \%$ \\
4 & & 1133.6 & $5.85 \%$ \\
\hline
\end{tabular}

As can be seen from Table. 3, the error that takes cost index and project hardware and software environment into consideration reached $1.06 \%$, which is lower than the $3.02 \%$ in the relevant literature. This shows that better predict the effect of the network can be used in real situation.

\section{Conclusions}

In this paper, the BP neural network is applied to establish the estimation model of frame structure multi-storey residential project cost. After training and learning, the model can achieve the desired results. Moreover, the trained network can quickly and reliably estimate the framework of multi-storey residential project cost, which indicates that is has a high precision, can achieve a quick quote and valuation requirements, and provide an efficient way for architecture project cost estimation. 


\section{References}

[1] Ren Hong, Zhou Qiming. Application of neural network for quick estimation of engineering construction cost and main quantities. China Engineering Journal, Volume 38, Issue 8 (2005), P. 135-138.

[2] Li Lihui, Hu Yueming, Chen Liancheng. Forecasting the plough area perpower of farm crop cultivation based on artificial neural network. System Engineering- Theory and Practice, Volume 9 (2000), P. 130-133.

[3] Wang Jianru. Prediction method of construction cost based on BP neural network. Journal of Shenyang Jianzhu University (Social Science), Volume 16, Issue 1 (2014), P. 42-45.

[4] Nie Guihua, Liu Pingfeng, He Liu. Study of forecast of building cost based on neural network. Engineering Science, Volume 10 (2005), P. 56-59. 